\title{
PERAN PENDIDIKAN AGAMA KRISTEN DALAM KELUARGA TERHADAP PERILAKU GENERASI MUDA
}

\author{
IRING LALO, NORYATI \\ Program Studi Pendidikan Agama Kristen Teologi Simpson \\ Email : iringlalo09@gmail.com, noryati707@gmail.com
}

\begin{abstract}
ABSTRAK
Pendidikan dalam keluarga dalam keluarga itu merupakan ibadah kita tanpa batas kepada Tuhan yang disembah, tidak ada batasan baik tempat dan waktu yang ingin digunakan, karena Pendidikan di sekolah dan gereja itu dapat dikatakan terbatas, Pendidikan Agama Kristen dalam keluarga ini adalah pendidikan yang nyata diberikan kepada anak-anak, tujuan pendidikan dalam keluarga untuk menggerkan hubungan anak kepada Tuhan, salah satu tujuan utama Pendidikan Agama Kristen dalam keluarga agar melatih kekompakan orang tua baik ayah dan ibu dalam mendidik anaknya, agar terlihat keharmonisan serta kehangatan keluarga dalam mendidik anakya dengan penuh cinta kasih, sehingga anak juga merasakan keharmonisan keluarganya dalam mencari Tuhan dalam keluarga, selain itu orang tua dapat melihat perkembangan anaknya, juga memberikan teladan yang baik bagi anaknya.
\end{abstract}

Kata kunci : Pendidikan Agama Kristen dalam Keluarga, Prilaku Anak

\begin{abstract}
Education in the family in the family is our worship without limits to God who is worshiped, there is no limit to both the place and time we want to use, because education in schools and churches can be said to be limited, Christian religious education in this family is real education given to children, The purpose of education in the family is to lead the child's relationship to God, one of the main goals of Christian Religious Education in the family in order to train the cohesiveness of parents, both father and mother in educating their children, to make it visible The harmony and warmth of the family in educating their children with love, so that the children also feel the harmony of their families in seeking God in the family, besides that parents can see the development of their children, as well as provide good examples for their children.
\end{abstract}

Keywords: Christian Religious Education in the Family, Children Behavior

\section{PENDAHULUAN}

Pendidikan Agama Kristen tidak hanya sebatas pembelajaran yang formal saja, juga bukan sebatas kurikulum yang di buat oleh Guru dengan sedemikian rupa, tetapi pendidikan kristen juga perlu dibangun dari dalam keluarga terlebih dahulu bertujuan untuk membentuk suatu sinergi yang kuat bersama dengan gereja dan sekolah. Karena ketiga hal tersebut saling berkaitan erat dan itu tidak dapat di pisahkan karena ketiganya itu memiliki peran atau tugasnya masing-masing dan itu sangatlah penting, sekolah tidak dapat berjalan dengan baik jika tidak ada dukungan dari gereja dan dan keluarga begitu seterusnya. Pernyatan tersebut didukung oleh Tafonao pengajaran tentang Tuhan serta pencipta-Nya diajarkan dari rumah atau keluarga.

Sehingga itu menyebabkan ketiga hal tersebut tidak dapat terpisahkan. (Amelia, 2018), mengatakan bahwa: (1) lemahnya Pendidikan Agama Kristen dalam Keluarga, disebabkan karena orangtua tidak ada konsisten dalam membimbing anak-anak. (2) Anak-anak remaja saat ini tidak melihat adanya figur yang dapat diteladani/model dalam keluarga. (3) Komunikasi face to face dalam keluarga jarang dilakukan, karena orang tua dan anak lebih asik dengan handphon masing-masing. Pernyatan diatas sependapat dengan Boiliu, Samalinggai, Setiawati bahwa di era digital ini anak-anak lebih senang bermain gadget daripada belajar, membantu orang tua, ikut kegiatan masyarakat, permainan tradisional mulai hilang karena anak lebih tertarik untuk bermain game di gadged. Sehingga untuk mengatasi itu Sihotang menjelaskan bahwa orang tualah yang harus mengatur watu penggunaan gadged pada anak, memberikan 
kedisiplin kepada anak dan yang terutama orang tua yang harus menjadi teladan kepada anakanaknya dirumah.

Berdasarkan kutipan di atas dapat diketahui bersama bahwa pendidikan dalam keluarga harus berperan aktif dan yang utama untuk memberikan cerminan yang baik bagi anak dirumah. Orang tua harus memberikan waktu mereka kepada anak-anaknya untuk dibimbing, orang tua memberikan teladan yang baik anak-anaknya, juga harus ada waktu untuk duduk bersama dengan anak-anaknya tanpa ada kesibukan lain sehingga memiliki komunikasi yang baik bersama anak.

Peran keluarga dalam pendidikan untuk memberikan bimbingan kepada anak-anaknya, karena pendidikan yang dapat diperoleh seorang anak tidak hanya diperoleh dari sekolah pormal saja, akan tetapi anak juga dapat memperoleh pendidikan dari luar sekolah seperti "Rumah, Lingkungan, Gereja" dalam hal ini peran orang tua sangat penting dalam pembentukan karakter, spiritual dan moral anak, dimana saja anak dapat belajar dengan maksimal, tugas PAK dalam hal ini untuk memberikan suatu pembelajaran secara mendalam tentang ketaatan, kesetiaannya dalam memperkuat imannya kepada Tuhan, pembelajaran tersebut di terapkan kepada siswa yang akan diajar, tidak anak kepada anak-anak saja tetapi berlaku untuk semua kalangan usia tanpa batas. Tidak dipungkiri banyak orang dewasa yang tidak mengerti dan tidak memahami akan hal tersebut, banyak juga yang mengaku percaya tetapi hanya sebatas tertulis di kartu identitas KTP saja, tetapi prilaku dan gaya kehidupan sehari-hari tidak mencerminkan bahwa dia orang yang percaya kepada Tuhan.

\section{METODE PENELITIAN}

Dalam penulisan ini penulis menggunakan penelitian pustaka. Penulis memberikan kajian terhadap sumber-sumber pustaka secara langsung yang digunakan serta menguraikannya kedalam sebuah uraian sehingga pembaca akan lebih mudah memahami dan mengerti apa yang sedang dibaca dan apa yang penulis ingin sampaikan dalam tulisan tersebut dapat tersampaikan dengan baik serta mudah untuk dipahami dengan menggunakan bahasa yang tidak terlalu tinggi, pembaca juga akan lebih mudah untuk menangkap pesan yang ingin di sampaikan melalui tulisan tersebut.

\section{HASIL DAN PEMBAHASAN}

\section{Pendidikan Agama Kristen}

Saba, Ezra Tari dan Rita dalam tulisannya mengatakan PAK adalah pembelajaran penting dalam keluarga. Penulis memaparkan bahwa Pendidikan Agama Kristen biasanya di kenal oleh masyarakat ialah suatu pembelajaran yang berkaitan erat dengan keagamawian, iman, spiritualias, ketuhanan, dan suatu pelajaran yang berkaitan dengan pengajaran tentang hubungan seseorang terhadap Tuhan atau sang penciptanya, seperti yang dikatakan oleh Ells, Saleky, Utami, Terok dan Nasrani bahwa pendidikan Agama Kristen itu merupakan suatu pembelajaran yang sangat penting untuk diajarkan baik dalam keluara maupun kepada semua orang. Akan tetapi Pendidikan Agama Kristen ini bukanlah suatu pembelajaran yang sangat mudah, juga bukanlah suatu pembelajaran yang dapat dikatakan sesuatu pembelajaran yang sepeleh, tetapi sebaliknya pembelajaran ini merupakan sutu pendidikan yang sangat penting dan harus berhati-hati. Karena ketika seorang guru salah mejelaskan maka itu akan salah tafsir atau salah dalam pemahaman anak, sehingga ilmu pendidikan PAK itu harus diperdalam dengan sungguh-sungguh. Berdasarkan pernyataan tersebut Sihotang dan Tarigan mengungkapkan bahwa pendidikan agama Kristen itu merupakan pembelajaran nilai moral yang juga harus ditanamkan kepada siswanya. Tentang ilmu ketuhanan, doktrin-doktrin akan Alkitab seorang guru haruslah memiliki pengetahuan yang benar untuk ini, kerena kesalahan terbesar yang di lakukan seorang guru ialah ketika melakukan pengajaran sesat kerena itu tidak hanya menyesatkan satu orang anak saja akan tetapi menyesatkan seluruh anak yang berada didalam kelas tersebut. 
Seperti yang dijelaskan oleh (Arozatulo Telaumbanua, 2018:13) "Guru harus melakukan gerakan pendidikan Karakter yang di mulai dari dirinya sendiri, yakni menjadi contoh bagi siswa yang kemudian di dukung oleh keluarga, gereja dan masyarakat." Seperti yang dikatakan di atas bahwa, yang seharusnya memulai untuk melakukan atau menerapkan pendidikan Karakter tersebut itu, kita memulainya dari pribadi guru tersebut, bagaimana siswa dapat berubah jika gurunya sendiri tidak bisa memberikan suatu teladan yang baik, sesuatu sikap atau tingkah laku yang dapat di tiru oleh siswanya. Oleh karena guru tidak dapat menoloak akan kebenaran ini, karena inilah yang sedang terjadi sekarang, gurulah yang harus memulainya terlebih dahulu.

Seorang penulis (Arozatulo Telaumbanua, 2018) mengatakan bahwa "seorang guru Pendidikan Agama Kristen tidak boleh mengabaikan perannya sebagi guru yang memiliki tanggungjawab membentuk karakter siswanya, artinya, Guru Pendidikan Agama Kristen tidak hanya sekedar mengajar, melainkan memberikan konstribusi yang sangat berharga lebih dari dari sekedar mengajar, yakni berusaha membentuk karakter siswa." Apa yang sudah dikatakan oleh Arozatulo Telaumbanua itu sudah jelas bahwa Guru Agama Kristen itu tidak boleh lupa akan apa yang menjadi tugas kewajibannya sebagai seorang guru, sebagai guru sejati ia harus memberikan suatu pembelajaran yang baik, benar dan berharga bagi anak didiknya, tidak hanya mengajarkan akan ketuhanan melainkan juga memberikan suatu pembelajaran pendidikan Karakter kepada anak didiknya sehingga memiliki karakter atau prilaku yang baik, karena seorang yang percaya kepada Tuhan itu di ciptakan dengan sangat baik dan sempurna, karena kita diciptakan segambar dan serupa dengan Allah, sudah selayaknyalah kita harus berusaha menjadi serupa dan segambar dengan Allah. Senada dengan pernyataan di atas Triposa, Arifianto dan Hendrilia mengungkapkan peran guru PAK iala untuk memperioritaskan untuk meningkatkan kerohanian anak dan gurulah yang harus berperan utama.

\section{Tujuan Pendidikan Agama Kristen dalam Keluarga}

Tujuan pendidikan agama kristen dalam keluarga karena orang tualah yang berperan pending dalam mendidik anak-anak saat berada dirumah, dan ini merupakan perintah Allah bagi semua umat-Nya. Salah satu tujuan utama pendidikan Agama Kristen dalam keluarga adalah untuk membina prilaku seorang anak, dalam suatu keluarga itu terus mendidik atau membentuk setiap anaknya dengan nilai-nilai kekristen, dengan etika-etika kristen, tentang bagaimana seorang kristen itu harus bersikap di tengah lingkungan masyarakat ataupun ketika ia sedang bersosialisai dengan siapa saja diluar rumah ataupun di luar gereja, sehingga inilah tujuan utama dari pendidikan PAK dalam keluarga Krsiten, ini membutuh keterlibatan dari kedua orangtua dan semua keluarga untuk terus memantau, membina atau membimbing anakanaknya agar dapat terus bertumbuh dengan baik di dalam pengenalan yang benar tentang Tuhan dalam hidupnya, salah satu tujuan PAK dalam keluarga untuk mendukung akan pendidikan PAK dalam Gereja, yang setiap minggu diajarkan digereja. Salah satu tujuan PAK agar pengetahuan pengenalan akan Tuhan itu tidak menyimpang atau tetap berada pada rel yang benar atau suatu jalan yang tepat. Pertumbuhan imannya semakin baik agar dia dapat mengenal siapa Tuhan yang ia percaya itu, percaya akan setiap mujizat yang dibuat, dapat menjadi saksi Kristus yang hidup di tengah-tengah masyarakat.

Seperti yang dikatakan oleh (Ruwi Hastuti, 2013) bahwa "Pendidikan Agama Kristen adalah pendidikan yang penting, sebab Pendidikan Agama Kristen adalah pendidikan yang memberikan landasan iman Kristen kepada setiap orang baik melalui keluarga, gereja dan sekolah." Apa yang dikatakan itu benar karena ketiga unsur tersebut saling berkaitan, tidak dapat di pisahkan antara sekolah, gereja dan keluarga, karena ketigahal tersebut sangat dibutuhkan dalam dunia pendidikan, karena dalam dunia pendidikan tidak dapat berjalan dengan baik jika tidak ada dukungan dari gereja dan keluarga, sehingga ini sangat diperlukan.

\section{Peran Penting Pendidikan Agama Kristen dalam Keluarga}


Pendidikan agama Kristen berperan penting Dalam bagian ini Penulis ingin menyampaikan pendapat bahwa salah satu alasan utama mengapa Pendidikan Agama Kristen dalam keluarga itu penting karena kita adalah keluarga Kristen, dalam sebuah rumah tangga atau keluarga itu sangatlah penting suatu pembelajaran atau pembinaan tentang keimanan, ketakwaan seseoarang terhadap keyakinnannya, ibadahnya, prilakunya dalam kehidupan sehari-hari, tentang bagaimana ia memiliki tanggungawab yang sangat besar adalah ia mampu menjadi terang dan garam dunia di tengah-tengah masyarakat yang belum mengenal kristus, kita di tuntut untuk dapat hidup sesuai dengan Firman Tuhan, mampu menerapkan apa yang diajarkan oleh Firman Tuhan bagi kita. Sehingga dalam sebuah keluarga keluarga berperan penting dalam pendidikan, selain untuk membina keluarga kepada jalan yang benar akan Allah, pendidikan Kristen dalam keluarga juga sebagai perpanjangan tangan dari pendidikan Kristen baik di sekolah maupun di gereja, sehingga ketiga hal itu tidak dapat dipisahkan karena ketiga hal tersebut saling berkaitan erat.

Sebagaimana yang dikatakan oleh (I. H. Enklaar, 1995) mengatakan bahwa keluarga merupakan tempat utama dalam tugas mendidik. Sebagai pemberian Tuhan yang tak ternilai harganya keluarga Kristenlah yang memegang peran penting dalam pendidikan agama Kristen. Seperti yang di katakan oleh I.H.Enklaar di atas sudah sangat jelas dan seharusnya menyadarkan kita sebagai orang Kristen, kitalah yang seharusnya berdiri paling terdepan, kita ujung tombak untuk mengajarkan anak-anak kita, untuk mendidik atau membina anak-anak kita tentang Kristen, tentang Tuhan yang kita sembah, karena ada begitu banyak sekolah guru yang bukan kristen mengajarkan pendidikan Kristen, seharusnya kita sebagai orang Kristen itu malu karena agama kita di ajarkan oleh orang yang bukan kristen.

Dalam tulisannya (Ruwi Hastuti, 2013) "Keluarga Kristen adalah tempat pendidikan yang pertama dan terutama bagi anak." Mengapa demikian karena kebersamaan yang indah adalah ketika berada ditengah-tengah keluarga, di sana juga kita mendapatkan pembelajaran yang sangat banyak dan bernilai, terutama soal waktu, kebersamaan, keluarga adalah harta yang sangat berharga bagi seorang anak. Dari keluarga anak mendapatkan banyakhal pembelajaran tentang kehidupan, moral, etika kehidupan dan banyakhal lainnya.

Kutipan dari (Ruwi Hastuti, 2013) mengungkapkan bahwa "Keluarga Kristen yang telah dikuasai oleh Tuhan Yesus, pasti keluarga itu menjadi taat dan kuat di dalam Tuhan dan mereka akan mengembangkan dan menantang pribadi-pribadi Kristen yang luhur. Keluarga Kristen merupakan suatu persekutuan antara anak-anak dengan orang tuanya, yang sanggup takut akan Tuhan dan menyembahnya." Tempat seorang anak dalam belajar adalah bermula dari keluarga, karena dalam keluarga ada orangtua yang senantiasa membantu dan membimbing, sehingga dari keluarga lah mental anak itu terus dilatih hingga mentalnya kuat utuk berani berada di antara orang banyak.

\section{Peran Orangtua dalam mendidik anak}

Dalam dunia pendidikan orangtua termasuk seorang yang sangat berpengaruh atau berperan penting dalam dunia pendidikan terutama jika sang anak telah keluar dari dalam kelasnya entah itu kelas sekolah minggu ataupun sekolah pendidikan, karena ketika si anak berada di dalam kelas waktu yang dipakai oleh guru itu sangatlah singkat juga terbatas, sehingga yang memiliki waktu yang sangat banyak dan leluasa itu adalah orangtua sang sanak, sehingga orang tua ketika berada dirumah bersama sang anak itu diharapkan agar dapat memberikan suatu pembelajaran, kepada si anak, karena ketika berada dalam rumah si anak memiliki waktu yang sangat banyak, sehingga disitulah orangtau memiliki kesempatan yang sangat banyak untuk belajar bersama sang anak sambil bermain dan memberikan rasa sayang dan perhatiannya.

Guru dan orangtua itu memiliki kerjasama yang baik dalam mendidik atau mengajar seorang anak karena guru mengajar anak disekolah untuk membantu orangtua dirumah sedangkan orangtua mengajarkan anak dirumah itu untuk membantu guru disekolah. 
Sebagaimana yang di kutip oleh (Talizaro Tafonao, 2018:128) "Keteladanan dan kebiasaan yang baik itu, sebaiknya diberikan oleh orang tua sejak dari kecil atau kanak-kanak karena hal itu dapat berpengaruh terhadap perkembangan anak. Oleh karena itu sebagai orang tua wajib memberikan pendidikan kepada anaknya". Jadi, sebagai orang tua yang baik dan sayang kepada anaknya, tentu saja tidak ingin anaknya memiliki kebiasaan atau prilaku yang tidak baik, tentu setiap orang yang terlah memiliki anak itu mengharapkan anaknya itu berprilaku yang baik dan santun terhadap siap saja termasuk orang tua. Oleh karena pendidikan Prilaku anak dalam hal ini juga perlu dibina dengan baik sejak dia kecil karena itu sangat muda untuk mengajarkan anak kecil darp pada mengajarkan orang tua, daya ingat anak itu sangat baik, sehingga ketika kita menanamkan nilai-nilai yang baik kepada anak sejak kecil maka itu akan melekat pada memori sangat anak.

Mengapa Prilaku itu penting untuk kita ajarkan kepada anak kita sejak dini karena kita sebagai orang kristen yang sudah pasti dan tahu akan kebenaran, kebaikan, kasih, dan nilai-nilai kekristenan lainnya, tentu saja setiap Ibadah hari minggu, sekolah minggu, kelas dan didalam rumah kita sendiri pun pasti pernah mengajarkan akan hal-hal tersebut, orang kristen di kenal oleh banyak orang awam itu adalah kasih, bukan hanya di lingkungan orang awam saja, di lingkungan orang kristenpun di tuntut supaya kita sebagai orang Kristen itu dapat menjadi berkat baik perkataan, tindakan ataupun prilaku kita setiap hari, menjadi terang dan garam ditengah masyarakat terutama bagi saudara-saudara kita yang belum mengenal Tuhan, sehingga ini perlu diajarkan kepada anak sejak dini.

Dalam sebuah Jurnal seorang penulis (Munirwan Umar, 2015) mengatakan "Orang Tua mampu menjadi motivator belajar anak". Jadi, orang tua adalah harapan bagi anak, tanpa dorongan, motivasi, semangat, doa, restu dari orangtuanya anak tersebut pasti tidak akan bisa melangkah, orang tua sangat berpengaruh bagi anak.

Satu kutipan dari (Dr. Hendarti Permono, Surakarta, 2013) menjelaskan bahwa "Pendidikan dalam keluarga sangat berperan penting. Pendidikan dalam keluarga sangat berperan dalam mengembangkan watak, kepribadian, nilai-nilai budaya, nilai-nilai keagamaan dan moral, serta ketrampilan sederhana". Mengapa pendidikan dalam keluarga dikatakan penting karena, waktu yang banyak bagi seorang anak ialah ketika ia berada didalam rumah, bersama dengan orangtuanya, sehingga inilah waktu yang baik bagi para orangtua untuk membantu guru disekolah, orangtua memberikan pembelajaran bagi anaknya dirumah, sebab orangtua tentu memiliki kebebasan tersendiri dalam mendidik anaknya sendiri.

\section{KESIMPULAN}

Dalam hal ini penulis ingin menyimpulkan bahwa tugas utama seorang PAK dalam keluarga ialah membawa segenap keluarga atau seisi rumahnya dalam pengenalan akan Tuhan baik secara pribadi maupun keluarga, karena itulah kewajiban atau tanggung jawab seorang PAK untuk membantu para guru di sekolah dan membantu guru sekolah minggu di gereja. Sehingga itulah yang menjadi Peran PAK dalam keluarga Kristen serta dengan tanggung jawabnya.

\section{DAFTAR PUSTAKA}

Tafonao Talizaro. (2018). Peran Pendidikan Agama Kristen Dalam Keluarga Terhadap Prilaku Anak, STT Kadesi Yogyakarta: Vol 3 No 2.

Arozatulo Telaumbanua. (2018). Peranan Guru Pendidikan Agama Kristen Dalam Membentuk Karakter Siswa, Jurnal STT Anugerah Misi Nias Barat: Vol 1 No 2

Munirwan Umar. (2015). Peranan Orang Tua Dalam Peningkatan Prestasi Belajar Anak, Jurnal Ilmiah Vol 1 No 1

Pitri Sartika Sihotang, Hermanto Sihotang, And Risa Ariska Tarigan, "Pengaruh Pendidikan Agama Kristen Dalam Keluarga Dan Rutinitas Kegiatan Ibadah Di Sekolah Terhadap Pembentukan Moral Siswa Di Sekolah Menengah Pertama Negeri 2 Pancur Batu," 
Phronesis: Jurnal Teologi Dan Misi 4, No. 1 (June 24, 2021): 53-72, Accessed September 3, 2021, Https://Jurnal.Sttsetia.Ac.Id/Index.Php/Phr/Article/View/125.

Dr. Hendarti Permono, Peran Orangtua Dalam Optimalisasi Tumbuh Kembang Anak Untuk Membangun Karakter Anak Usia Dini, 2013. Psikologi Universitas Persada Jakarta

Ruwi Hastuti, Pendidikan Agama Kristen Dalam Keluarga Sebagai Pusat Bermisi 2013, STT Intheos Surakarta

Elena Saba, Ezra Tari, And Rita, "Implementasi Pendidikan Agama Kristen Dalam Keluarga Melalui Gereja," Bonafide: Jurnal Teologi Dan Pendidikan Kristen 1, No. 2 (December 20, 2020): 218-233, Accessed September 3, 2021, Http://Jurnal.Sttissiau.Ac.Id/Index.Php/Jbs/Article/View/17.

Natasia Irene, Peran Pendidikan Agama Kristen Dalam Keluarga Terhadap Perilaku Anak, preprint (Open Science Framework, November 18 2020), (accessed September 1, 2021) https://osf.io/p84ds.

Fredik Melkias Boiliu and Meyva Polii, "Peran Pendidikan Agama Kristen dalam Keluarga di Era Digital terhadap Pembentukan Spiritualitas dan Moralitas Anak," Immanuel: Jurnal Teologi dan Pendidikan Kristen 1, no. 2 (October 31, 2020): 76-91, accessed September 1, 2021, http://stt-su.ac.id/e-journal/index.php/immanuel/article/view/18.

Yunardi Kristian Zega, "Pendidikan Agama Kristen dalam Keluarga: Upaya Membangun Spiritualitas Remaja Generasi Z," JURNAL LUXNOS 7, no. 1 (June 25, 2021): 105-116, accessed September 2, 2021,

Natasia Irene, Peran Pendidikan Agama Kristen Dalam Keluarga Terhadap Perilaku Anak, preprint (Open Science Framework, November 18, 2020), accessed September 1, 2021, https://osf.io/p84ds.

Fredik Melkias Boiliu, Kaleb Samalinggai, and Devi Wahyu Setiawati, "Peran Pendidikan Agama Kristen Di Era Digital Sebagai Upaya Mengatasi Penggunaan Gadget Yang Berlebihan Pada Anak Dalam Keluarga Di Era Disrupsi 4.0" (n.d.): 14.

Lamris Sihotang et al., "Peran Orang tua Mengatasi Dampak Negatif Gadget pada Remaja Kristen" 1, no. 1. (2021): 10.

Reni Triposa, Yonatan Alex Arifianto, and Yudi Hendrilia, "Peran Guru PAK sebagai Teladan dalam Meningkatkan Kerohanian dan Karakter Peserta Didik," Jurnal Pendidikan Agama Kristen (JUPAK) 2, no. 1 (June 16, 2021): 109-126, accessed September 3. (2021). https://ejurnal.sttkadesiyogyakarta.ac.id/index.php/jupak/article/view/24. 